\title{
Problems with L2 classroom research in the SEN setting with visually challenged learners
}

\begin{abstract}
The paper highlights the what, the why and the how questions which may be posed by the novice researcher in the field of visual impairment. I discuss the problematic issues inherent to various stages of research preparation and implementation such as selection of a research method, recruitment of subjects for a study, the lack of theories and models in the field of visual impairment, applicability and administration of standard tests in the SEN setting, keeping up participants' commitment throughout a project, or sustainment of the researcher's emotional involvement.
\end{abstract}

KEYWORDS: classroom research, special education, visually impaired learners, blind learners.

\section{INTRODUCTION}

From reading SLA research manuals one may have an impression that conducting any research is a fairly straightforward exercise provided all suggested steps are observed and plans are realistic (Richards 2003) or 'it is like going to the professional theatre - it all looks so easy, so professional' (Schachter, Gass 1996: viii). However, since there are no SLA research manuals with the guidelines on how to conduct various types of research with the SEN students, the novice researcher may lack the competence on how to approach the SEN reality. The main objective of the paper is to present in detail the problems related to conducting classroom research in the special education needs (SEN) setting. An insight is given into the research in the field of visual impairment. Hence, reflecting on my experiences and endless hurdles while carrying out the research, I make an attempt to provide some advice on how to overcome research-related inconveniences. My intention is not however to discourage but rather persuade potential L2 re- 
searchers to embark on this demanding but greatly rewarding endeavour of conducting classroom research with blind and visually impaired learners (BVILs).

Needless to say, classroom research is a challenge even for experienced researchers or teachers. Numerous variables inherent to this type of research make frequently its results unpredictable. In the case of the SEN setting, particularly in the context of The BVILs, classroom research is even more problematic. The available methodological literature in the field of L2 research provides some advice on dealing with challenges typical of classroom research carried out in the mainstream education setting. Nevertheless, one can hardly find any information on applicability of these research tips to the SEN setting.

Indisputably, the specific parameters of the two settings differ. Likewise, the problems the researchers encounter while doing research. There are many questions that may appear on a way related to research preparation and implementation, which have not been explicitly dealt with SLA research literature.

\section{MAJOR PROBLEMS AT THE STAGE OF RESEARCH PLANNING}

According to Marshall and Rossman (2006: 72-73) researchers in each context need adequate preparation involving 'extensive discussion of a plan for dealing with issues before they present dilemmas and also as they may arise in unanticipated ways in the field, using the advice and experience of previous scholars'. In the first place, the researcher needs to discuss the what, the why, and the how of research activities in the field of visual impairment. As Tobin (2011: 20) notices the research institutions have to prioritise their activities, especially considering the fact of a worldwide economic depression. Research in visual impairment has to justify its place alongside a multitude of other demands and activities. The researchers in the area of the visual impairment have usually practical or 'applied' concerns. They attempt to investigate physiological sides of visual impairment such as the absence of the sensory modality i.e. vision on generating knowledge and understanding the surrounding reality (see for details Jedynak 2011b).

L2 classroom research in the BVILs setting seems to be justified for two reasons. Firstly, this category of learners has a great potential for second/foreign language learning and are able to achieve success in L2, especially in the phonetic/phonological domain (for details see Jedynak in print). Giftedness of the BVILs has been reported in various areas including foreign language learning (for details see Jedynak 2009). Secondly, there is still much 
to be done in the field of visual impairment, especially typhlomethodology of foreign language learning and teaching. This observation is also made by Bak (2011: 26) who claims that there is 'a call for the greater use of researchbased instructional practices in the field of visual impairment'. Nowadays, there is a great demand for interdisciplinary research activities crossing out the territory of typhlopedagogy, SLA, neurolinguistics and psycholinguistics (for details see Jedynak 2011a). The main areas of investigation are related to 1) enhancing The BVILs' motivation towards foreign language learning; 2) improving teaching and learning process' 3) developing the BVILs language learning autonomy through implementation of IT solutions and the European Language Portfolio for the Blind and Visually Impaired Learners (ELP BVIL); 4) establishing learning strategies effective for the learners with vision deficit. All the above mentioned areas seem to be fully justified for research which, if followed with effective dissemination of its findings, may contribute to good practices policy in language classrooms. Considering the predispositions of the BVILs for foreign language learning, the investigation into the fourth suggested areas may allow the learners to realize their full human potential at school and later on in adulthood in which the command of English is an unquestionable asset. In view of Tobin's argument mentioned earlier on economic crisis and prioritisation of research, it seems that L2 classroom research with its practical dimension may contribute to the new workplaces formation for the community of visually challenged people.

Once the what and the why about the research have been settled, the researcher needs to answer the how question. There are some technical procedures common to all investigations. Analysing available classroom research in visual impairment described in the Journal of Visual Impairment and Blindness in the last couple of years, one may notice some trends in research design. The overwhelming majority of research represents teacher action research, case studies, or qualitative research. Teacher action research seems to be a very productive method providing information and creative solutions related to teaching/learning processes in the BVILs from those who are directly involved in educational services. After identifying a problem, a researcher should come up with a plan, or a particular action he/she intends to take. Zebehazy (2011: 39), for instance, recommends for the Braille student creating a warm up sheet or a set of flashcards containing thirty or forty frequently occurring words in reading texts. These words should not be sounded out. The researcher's action plan may drive the research question: to what extent does daily exposure to flashcards or frequently occurring words improve the students' fluency when reading? There are also many studies in the field of visual impairment which reflect a qualitative methodology (e.g. Smith 2008). As Kirchner (2003) notices the reliance on qualitative 
methods occurs due to difficulties in conducting quantitative research among the low-prevalence population that are visually impaired representing identical or very similar characteristics. For the above mentioned reason quantitative studies relying on descriptive statistics are not very common and they seem to have been conducted on a national level through the auspices of education department. The national scope of these studies and adequate funds allow the researcher to oversample the population of visually challenged learners, such that approximately 1000 subjects participate in each study. In the European Union collaborative research subsided by charitable partners are popular. In Poland, however, finance is a dominant issue in planning this type of research. The novice researcher should have the awareness that the preparation of various Braille resources for the purpose of conducting the research requires some effort and funds.

Judgement about which research method is best for L2 researcher depends primarily on the nature of the questions being asked and the extent of prior knowledge on the topic. Creswell (2002) enumerates three criteria for research method selection: 1) the research problem; 2) the personal experiences of the researcher, and 3) the audience who will utilize the research when completed. It seems that mixed methods design is the most suitable for the research among the BVILs since it may overcome the limitations related to the low-prevalence population. Undoubtedly, one way of reducing some of the possible limitations is the implementation of the longitudinal study in which the same group of the BVILs are observed regularly over a prolonged period of time. The literature reports on such long-term monitoring of linguistic development of the blind children (e.g. Fraiberg 1977).

Whatever the research topic and the research method, some technical procedures used in low-prevalence conditions such as visual impairment or blindness are common to all investigations. Recruitment of subjects for the purpose of any research seems to be a difficult task, but it is even more complicated in the case of the BVILs. Random sampling of such subjects is not advisable. Accurate data of the sample group, its number, age range, causation and degree of the visual impairment, the age of onset of the condition, the presence and nature of additional disabilities are necessary to plan and implement research. To obtain relatively reliable research results one needs to screen the potential subjects in terms of cognitive development and visual impairment. Since vision deficit, whether it is partial or full, may be correlated to cognitive or/and emotional deficiencies, researchers need first to get acquainted with the BVILs' school files and medical data to identify the learners representing a similar level of cognitive development. Frequently, school counsellors and tutors may inform the researcher on the BVILs' psycho-emotional and cognitive condition and their educational background. In 
the low-prevalence population research, the researcher frequently faces a problem of the availability of possible and willing to cooperate participants. Since it is difficult to find the subjects all of whom can meet the same criteria, the validity and generalisability of the research results may be easily undermined. However, it should not discourage the researcher from making attempts in L2 classroom research only because he/she cannot meet specific scientific demands.

Another aspect of sampling process which needs to be considered is the vision condition of the potential subjects. The congenitally blind learn from formal instruction differently than the partially sighted or the adventitiously blind which lost their sight at some stage of their lives. Undoubtedly, the age at which vision was lost influences the learning and teaching process. The congenitally and adventitiously blind learners rely exclusively on auditory and tactile learning. Consequently, they interact with teachers and peers differently. The nature of comprehensible input in the FL classroom needs also to be adjusted to the specific individual needs of the BVI students. Therefore, classification of the visually challenged learners into various visual function groups seems to be an essential step at the research planning phase. By and large the researchers divide the visually challenged learners into three groups: 1) these who are congenitally blind, 2) these who lost vision in very early childhood and are not able to rely on any visual memories, 3) these who lost vision in childhood or adulthood and are able to rely on visual memories, and 4) these who represent any form of visual and cognitive dysfunction due to disorders of the parts of the brain subserving visual function. The subjects may be also categorized on the basis of the NORDSYN classification system in which learners fall into 5 groups $(0-$ normal/subnormal vision; A - low vision; B - social blindness; C - near total blindness; D - total blindness) (Riise 1993).

With regard to planning L2 classroom research it is also worth mentioning that the researchers usually generate their hypotheses on the basis of some theories. So far, there are no models or general theories in the field of visual impairment research. Theories are necessary as they guide research. Tobin (2011: 23) analysing the problem of the lack of theories in his article notices that it may due to the fact that the field of visual impairment is 'too vast and heterogeneous an area of study for a single over-arching theory or model to be envisaged or practicable'. However, there is one research model proposed by Warren (1984) which may serve as the basis for other researchers. In his hierarchical model a factor or a variable is not to be measured independently, but rather in its wider psychological and social contexts. Furthermore, it should be analysed in the long-term study to observe its evolution over time. Warren's approach may be called a model for action 
since it is bound up to a strategy or a plan for an action. The researcher should, as Warren claims, collect first 'an integrated body of knowledge about blind learners (their sensory learning, language, and social aspects, sex, intelligence, residual vision, age, and acquired characteristics). As Tobin (2011: 23) notices in this way 'other researchers would have a comparative base against which to plan and place their own new investigations and to evaluate their data'. It is also worth considering Tobin's personal way of dealing with various problematic aspects in the field of visual impairment. Unlike Warren, Tobin does not formulate any model for action, but rather a typical theory. In line with this theory delays and barriers experienced by blind learners have as their causation the lack, the inadequacy or the inaccessibility of information (Tobin 2008: 119). This theoretical ground is a good starting point for the researchers who may observe in the L2 classroom the consequences of the lack of information such as problems with understanding some concepts, especially the abstract ones.

It is necessary to mention that any research with the visually challenged learners needs to be in accord with the school regulations and the requirements of Data Protection Act. Ethical clearance should be obtained from the researcher's affiliation. Furthermore, consent forms for research participation should be requested from the BVI students or their parents. As a rule, the researchers prepare the leaflets explaining the purpose of the study and various notification documents for the school authorities and teachers.

\section{MAIN PROBLEMS AT A STAGE OF PROJECT IMPLEMENTATION}

In the SEN setting, the researcher faces many challenges related to conducting research since he/she is tempted to implement L2 research methodology and instruments commonly applied in the mainstream education, which may give rise to invalid and unreliable research findings. The predictive ability of a test that uses norms based on a sighted population is also questioned by practitioners who conduct comparative research with VIBLs and sighted learners. For this reason, the researcher should first make sure whether the visually impaired learners are also eligible for a particular standard test and if not, approved batteries and tests with appropriate norms should be applied. Some standard tests based on the sighted learners' norms can be still used by psychologists for qualitative evaluations. Though normative samples based on the visually impaired are available, the researcher needs to be cautious since some of them are dated. Norms established for the visually impaired should be different from these for the congenitally or adventitiously blind learners. They should also be random and representa- 
tive of the general population of either the people with visual impairment or without any vision specifying details about the selected group (e.g. amount of vision, age, specific age of onset of the condition). There are many tests which have been adapted to a population of the people with visual impairment such as learning aptitude tests or intelligence tests. All of them are a performance-based measure for the blind and partially sighted adults, designed to be used either independently of or with the verbal scale. The use of such tests is justified considering the fact that the learners with vision deficit cannot rely on a visual mode like their sighted counterparts and they follow a different learning and information processing route. Adaptation of a test to the specificity of the BVILs may be done by the researcher. For example, in the action research in which I investigated the relationship between autonomous tasks in L2 learning and attributional shifts in visually challenged learners of English, there was a need to adjust a question in a Polish version of a standard test for measuring Locus of Control (Krasowicz, Kurzyp-Wojnarska 1990). The situation described in the question related to anxiety experienced in everyday life of normally sighted individuals (When you go through a tunnel or you look down from the great height) cannot correspond to the state of apprehension experienced in the same situation by visually impaired or blind people. Thus, some transformation of the question seemed advisable (When you hear unexpectedly a high pitch sound or you find yourself alone in the open space).

Once the researcher selects an appropriate test, he/she needs to administer it. Undoubtedly, Braille test takers need twice as much time than visually impaired learners for a test completion. Frequently, the researcher or the classroom teacher reads out the test or questionnaire questions to the Braille readers. Motivating visually challenged L2 learners towards active participation in a FL lesson or a project may be a challenge for the researcher (Jedynak 2010). The BVI research participants are frequently anxious about being observed or finding themselves in a testing situation. Thus, the researcher needs to adopt a flexible approach to his/her research plan. Being sensitive to their anxieties may be accomplished by offering sympathetic comments, being able to reschedule at the last minute if participants need to have some time off. Furthermore, the researcher should be open about the required responsibilities emphasizing at the same time research benefits. Some requirements, such as active involvement in classroom interactions, often put the BVILs off engaging in research projects. A supportive and developmental rather than judgemental approach may however enhance research participants' motivation. What I do in my research prior its introduction and throughout its implementation is stressing the value of the project in terms of the learners' own personal gains. Furthermore, the researcher may also 
make subjects aware of the significance of L2 research for the whole community of visually challenged people. From my observations more BVILs than their sighted counterparts have a tendency to display a negative attitude towards foreign language learning. Frequently, it is more difficult to make the former involved in any extra curriculum activities such as participation in a FL project. For the same reason L2 classroom research in the field of visual impairment is more demanding than the one in the mainstream education setting. Many BVILs do not come willingly into interactions with a FL teacher or other peers as they bring into a classroom their fears and inhibitions. Keeping up the BVILs' commitment throughout L2 classroom research is however possible provided the researcher uses skilfully various techniques aimed at enhancing research participants' motivation. One of them is showing the benefits of FL learning such as communication in the target language and new opportunities for the people with vision deficit who may realize their professional aspiration as interpreters or FL teachers.

What is not discussed in the research manuals but definitely needs to be mentioned with regard to the L2 classroom research in the field of visual impairment is the problem of handling physical and emotional strain experienced by the researcher, especially by the novice researcher. Pasquero, Schmitt, and Beaulieu (2001) notice the importance of personal and psychological factors claiming that they are as demanding as methodological ones, sometimes to the point of undermining the researcher's motivation to pursue. My intention is not just to warn other researchers of the stress they may experience and discourage them from doing research but rather provide some practical and specific suggestions and prepare them for the realities of conducting L2 classroom research with the BVILs. Observing students and teachers, recording their performance and/or interactions in a classroom, and maintaining meticulous field notes throughout requires a great effort from the researcher, who frequently has to put aside anxiety and weariness while collecting data. As a result, there is little time to write elaborate reflections and the purpose of research may seem questionable. If the researcher is a teacher at the same time, research may be even a greater emotional burden. Research objectives may not be attained due to various unpredictable and unavoidable situations such as decrease in participants' motivation or lack of their involvement in classroom activities or interviews with the researcher. Frequently research objectives are attained but it takes more time to conduct research due to all the hurdles the researcher faces on his/her way which have been discussed above. Novice researchers in the field of visual impairment should also bear in mind that apart from vision deficit or its loss they may also expect other dysfunctions of research participants (e.g. hearing problems, problems with mobility), which may make data collection diffi- 
cult. It seems advisable to prepare additional data collections methods after the primary data collection has been completed. This strategy will reduce the stress of having only limited time for ongoing data analysis. It may be achieved by asking participants' permission to contact them for clarification or more information after the actual research. Another strategy which has considerable therapeutic value is keeping a research journal. Storing various thoughts and main incidents may be a good base for developing elaborate reflections when the researcher is outside a research context. If it is possible it is worth recording immediate insights on a dictaphone and working with them when anxiety is less intense. Finally, the researcher should keep some distance which ensures objectivity of data collection. Empathizing with participants is good as long as it does not affect the researcher's independent judgements, his/her both physical and mental health. However involved in L2 classroom research in the BVILs context, one needs to remember it is still just research. Richards (2003: 236) puts it in the best words 'Always remember that you're not trying to change the whole world - just come to a better understanding of some small aspects of it'.

\section{FINAL CONSIDERATIONS}

Despite all the hurdles the researcher needs to overcome while conducting L2 classroom research, its positive value for the field of visual impairment is unquestionable. Similarly to the classroom research in mainstream education, the SEN research attempts to identify those characteristics of the L2 classrooms that lead to efficient learning of the BVILs. Effective research is based on well-reasoned theory and synthesis of previous knowledge. However, typhlomethodology is still at the stage of theories and models formation. There is still much to be done in the field. The issues such as learner behaviour, teacher talk, interactions in the BVILs classroom, and effectiveness of instructed learning are only a few suggestions for further research. Furthermore, comparative studies of sighted learners and partially sighted or congenitally blind or adventitiously blind learners in the above mentioned areas are of special significance since they shed some light on how various types of learners process information and what strategies they apply to learn foreign languages. Undoubtedly, the BVILs and eventual beneficiaries of L2 classroom research constitute a unique population. The researcher may be puzzled at discrepancies among participants, some of whom may be delayed linguistically and cognitively while others may surpass sighted individuals in terms of their memory, linguistic abilities, especially these related to phonology/phonetics. If motivated properly, they all 
may become cooperative and inquisitive FL learners, pushing researchers beyond the intended purpose or investigative goals. The BVILs context makes the study of L2 classrooms a rewarding experience, especially when the research participants through research implementation build up their learning motivation and become more aware of their language learning needs.

\section{REFERENCES}

Bak, S., 2011. Types of research: Quantitative, qualitative, mixed methods, and teacher action. In: The Educator. Vol. XXIV, issue 1. A publication of ICEVI, 26-31.

Creswell, J.W., 2002. Research design: Qualitative, quantitative, and mixed methods approaches. New York: Sage Publications.

Fraiberg, S., 1977. Insights from the blind. New York: Basic Books.

Jedynak, M., 2009. Gifted Visually Impaired Children Learning Foreign Languages. In: Pawlak M. (ed.). Studies in Pedagogy and Fine Arts. New Perspectives on Individual Differences in Language Learning and Teaching. Vol. VIII. Poznań-Kalisz: Adam Mickiewicz University, Faculty of Pedagogy and Fine Arts in Kalisz, 337-347.

Jedynak, M., 2010. Foreign Language Motivation - Some Deliberations on its Enhancement in Visually Impaired Learners. In: Michońska-Stadnik A. (ed.). Anglica Wratislviensia XLVIII. Wrocław: Wydawnictwo Uniwersytetu Wrocławskiego, 171-182.

Jedynak, M., 2011a. Across the Borders of Typhlopedagogy and L2: New Research Problems, Recent Findings, Perspectives. In: Pawlak, M. (ed.). Extending the Boundaries of Research on Second Language Learning and Teaching. Part V. Berlin-Heidelberg: Springer, 263-275.

Jedynak, M., 2011b. Językowe odwzorowanie rzeczywistości przez niewidomych i widzących użytkowników języka polskiego. In: Rozprawy Komisji Jezzykowej XXXVIII. Wrocław: Wrocławskie Towarzystwo Naukowe, 61-73.

Jedynak, M., in press. Nauczanie wymowy języka obcego w kontekście ucznia niewidomego. In: Proceedings of the V Scientific Conference 'Language-Literature-Culture' held at Higher Vocational School in Płock, Poland 9-10th May 2011.

Kirchner, C., 2003. Guest Editorial. In: Journal of Visual Impairment \& Blindness. 97 (5), 259.

Krasowicz, G., Kurzyp-Wojnarska, A., 1990. Kwestionariusz do badania poczucia kontroli (KBPK). Warszawa: Pracownia Testów Psychologicznych Polskiego Towarzystwa Psychologicznego.

Marshall, C., Rossman, G.B., 2006. Designing qualitative research (4th ed.). Thousand Oaks, CA: Sage.

Pasquero, J., Schmitt, R., Beaulieu, S., 2001. Facing the reality of qualitative research: An interactive workshop comparing teaching and research case writing. In: Klein, H. (ed.), Proceedings of the $18^{\text {th }}$ International Conference on Case Research and Application (WACRA) 17-29. Lund: Sweden.

Richards, K., 2003. Qualitative inquiry in TESOL. Basingstoke: Palgrave Macmillan.

Riise, R., 1993. Nordic registers of visually impaired children. In: Scandinavian Journal of Social Medicine 21: 66-68.

Schachter, J., Gass, S. (eds), 1996. Second language classroom research: Issues and opportunities. Mahwah, NJ: Lawrence Erlbaum. 
Smith, T.M., 2008. Adaptation to low vision caused by age-related macular degeneration: A case study. In: Journal of Visual Impairment and Blindness, 102 (11), 725-730.

Tobin, M., 2008. Information: A new paradigm for research into our understanding of blindness? In: British Journal of Visual Impairment, 26, 119-127. doi: 10.1177/0264619607088278

Tobin, M., 2011. Is research necessary? In: The Educator, vol. XXIV, issue 1, 20-25.

Warren, D.H., 1984. Blindness and early childhood development (2 ed., rev'd.). New York: American Foundation for the Blind.

Zebehazy, K., 2011. Call to action: Contributing to research through your everyday teaching experience. In: The Educator, vol. XXIV, issue 1, 38-44. 